\title{
Preoperative pulse and thermal radiofrequency facilitates prehabilitation and subsequent rehabilitation of a patient scheduled for total knee arthroplasty
}

\author{
Francesco Carli, MD, MPhil · Daniel Chora, MD - Rashami Awasthi, BSc • \\ Juan Francisco Asenjo, MD · Pablo Ingelmo, MD
}

Received: 10 June 2015/Revised: 19 August 2015/Accepted: 1 September 2015/Published online: 2 October 2015

(c) Canadian Anesthesiologists' Society 2015

\section{To the Editor,}

The presence of pain and frailty ${ }^{1}$ (in part defined as poor strength and flexibility and limited capacity to complete physiological tasks) has been shown to be a consistent predictor of poor recovery from knee surgery. ${ }^{2}$

This letter describes the use of pulsed and thermal radiofrequency (PRF and TRF) denervation, followed by a six-week preoperative prehabilitation program $^{3}$ to strengthen the physical function of a 79-yr-old elderly Caucasian female (non-smoker, body mass index 24 $\mathrm{kg} \cdot \mathrm{m}^{-2}$ ) with severe osteoarthritis of the knee requiring total knee arthroplasty. She was suffering from significant knee pain unrelieved by opioid medication (codeine 30 $\mathrm{mg} /$ paracetamol $325 \mathrm{mg}$ six times a day and pregabalin 50 $\mathrm{mg}$ twice a day) and had severely impaired functional activity, poor nutritional status, and moderate depression. In view of her relatively large opioid consumption, she agreed to radiofrequency (RF) denervation of the affected knee.

Using a RF technique based on the recent and novel description of innervation of the anterior knee, ${ }^{4}$ the right saphenous nerve was approached at the adductor canal using ultrasound guidance. Saline $(0.9 \%) 2 \mathrm{~mL}$ was injected beside the saphenous nerve in the adductor canal prior to PRF treatment using the RF device, OWL sterile single-use (disposable) RF cannulae, and an OWL URF3AP (ML) RF generator (Diros Company, Markham, ON, Canada) for four minutes at $42^{\circ} \mathrm{C}$. Ropivacaine $(0.5 \%) 10$ $\mathrm{mL}$ was then injected near the saphenous nerve. Next, the genicular terminal branches of the sciatic and femoral

F. Carli, MD, MPhil ( $₫) \cdot$ D. Chora, MD · R. Awasthi, BSc · J. F. Asenjo, MD · P. Ingelmo, MD

Department of Anesthesia, McGill University Health Centre, Montreal General Hospital, Montreal, QC, Canada

e-mail: Franco.Carli@mcgill.ca nerves were also treated with continuous $\mathrm{RF}$ for two minutes at $80^{\circ} \mathrm{C}$ using a $10-\mathrm{mm} 18 \mathrm{G}$ active tip RF curved needle (OWL sterile single-use (disposable) RF cannulae), and then ropivacaine $(0.5 \%) 2 \mathrm{~mL}$ and methylprednisolone $10 \mathrm{mg}$ added to the local anesthetic were administered to each nerve. Finally, two pulses of PRF treatment were applied for four minutes at $42^{\circ} \mathrm{C}$ inside the knee joint on each recess beside the patella.

After the block, the patient experienced complete pain relief (numerical pain rating scale $=1$ at rest and 3 on movement: $0=$ no pain and $10=$ worst pain experienced for the patient) until surgery with no need of any analgesics. Following the RF treatment, the patient started her six-week multimodal prehabilitation program which included aerobic and resistance exercises three times a week, nutritional optimization by providing $\left(20 \mathrm{~g} \cdot \mathrm{day}^{-1}\right)$ a whey protein supplement (taken within one hour following exercise in order to maximize muscle protein synthesis), and daily relaxation strategies (imagery, visualization, deep breathing exercises). The program resumed at home on week two after surgery and included the specific physiotherapy exercises from week two to eight and the pool exercises from week four to eight.

The knee arthroplasty was performed under spinal anesthesia, and for postoperative analgesia, the patient received a continuous femoral blockade catheter with ropivacaine $(0.2 \%) \quad 5 \mathrm{~mL} \cdot \mathrm{hr}^{-1}$ for two days and subsequently acetaminophen $1 \mathrm{~g}$ four times a day, Celebrex $200 \mathrm{mg}$ twice a day, and tramadol $50 \mathrm{mg}$ iv three times a day. Ambulation started with the help of a physiotherapist on the first postoperative day, and the physiotherapy continued until discharge on the fourth postoperative day. The Table reports the changes in various domains during the prehabilitation period and up to eight weeks following surgery. The excellent preoperative 
Table List of outcome measures

\begin{tabular}{|c|c|c|c|c|}
\hline Outcome Measures & Baseline & Preoperative & 4 weeks after surgery & 8 weeks after surgery \\
\hline TUG (sec) & 16 & 8 & 10 & 10 \\
\hline 6MWD (metres) & 214 & 302 & 300 & 350 \\
\hline Energy Expenditure $\left(\mathrm{kcal} \cdot \mathrm{kg}^{-1} \cdot \mathrm{week}^{-1}\right)$ & 18 & 37 & 8 & 64 \\
\hline \multicolumn{5}{|l|}{36 Item Short Form Survey (SF-36®) } \\
\hline PCS & 20 & 25 & 22 & 39 \\
\hline MCS & 38 & 60 & 51 & 68 \\
\hline \multicolumn{5}{|l|}{ HADS } \\
\hline Anxiety & 5 & 1 & 4 & 2 \\
\hline Depression & 5 & 3 & 7 & 2 \\
\hline \multicolumn{5}{|l|}{ WOMAC } \\
\hline Pain & 15 & 8 & 10 & 6 \\
\hline Stiffness & 4 & 4 & 5 & 3 \\
\hline Physical Function & 53 & 38 & 37 & 25 \\
\hline VAS & 8 & 1 & 6 & 1 \\
\hline
\end{tabular}

6MWD = six minute walk distance: distance covered over $6 \mathrm{~min}$; (patient 's age-adjusted predicted value, $540 \mathrm{~m}$ ); lower distance indicates decreased functional capacity

HADS = Hospital Anxiety and Depression Scale: score $>5$ indicates moderate to severe state of anxiety and depression

PCS $=$ Physical Component scale MCS = Mental Component scale. The scales are indices of quality of life: scores $>50$ indicate better health states

TUG = time up and go; time to start up walking 3 metres and come back; higher score than 10 sec indicates limited independent function

VAS $=$ visual analogue pain scale $(0-10) ; 0=$ no pain; $10=$ worst imaginable pain

WOMAC $=$ Western Ontario and McMaster Osteoarthritis Index: pain score (0-20), stiffness score (0-8), physical function score (0-68); higher scores indicate worse pain, stiffness and functional limitations

analgesia allowed significant improvement in all the objective and self-reported outcome measures recorded during the six weeks before surgery and the eight postoperative weeks. The high quality of analgesia achieved with the RF had a major impact by facilitating the implementation of prehabilitation and rehabilitation. In addition, the physical training likely played an important role in enhancing the patient's physical strength.

This case illustrates that analgesia achieved by PRF may facilitate the implementation of prehabilitation programs in patients experiencing severe pain that can lead to decreased functional capacity and physical strength while waiting for total knee arthroplasty. In addition, prehabilitation might enhance the physical and emotional reserve to overcome the stress of surgery and accelerate the rehabilitation process. An appropriately designed and adequately powered clinical trial is needed to confirm these findings.
Conflicts of interest None declared.

\section{References}

1. Beggs T, Sepehri A, Szwajcer A, Tangri N, Arora RC. Frailty and perioperative outcomes: a narrative review. Can J Anesth 2015; 62: 143-57.

2. Kennedy DM, Hanna SE, Stratford PW, Wessel J, Gollish JD. Preoperative function and gender predict pattern of functional recovery after hip and knee arthroplasty. J Arthroplasty 2006; 21: 559-66.

3. Carli F, Zavorsky GS. Optimizing functional exercise capacity in the elderly surgical population. Curr Opin Clin Nutr Metab Care 2005; 8: 23-32.

4. Franco CD, Buvanendran A, Petersohn JD, Menzies RD, Menzies $L P$. Innervation of the anterior capsule of the human knee: implications for radiofrequency ablation. Reg Anesth Pain Med 2015; 40: 363-8. 